\title{
Development of a Thermal Equivalent Circuit to Quantify the Effect of Thermal Paste on Heat Flow through a Permanent Magnet Alternator
}

\author{
Mehmet C. Kulan \\ Newcastle University \\ Newcastle Upon Tyne, NE1 7RU, UK \\ m.c.kulan@ newcastle.ac.uk
}

\author{
Nick J. Baker \\ Newcastle University \\ Newcastle Upon Tyne, NE1 7RU, UK \\ Nick.baker@newcastle.ac.uk
}

\begin{abstract}
This paper describes the thermal modelling of a permanent magnet alternator (PMA). The principal focus is to investigate the effect of adding thermal paste into the machine end winding region. A thermal lumped parameter network is proposed to quantify the change in heat flow paths for a flange mounted alternator. The thermal model is implemented in Simulink, which allows many different heat paths to be easily combined. Since addition of a thermal paste introduces new axial heat flow by conduction paths between the stator windings and frame, the developed thermal network considers the detailed heat flow paths in the PMA. The thermal network is extended to the machine frame and part of the mounting plate. It is shown that axial heat flow has been improved $5.6 \%$ for the PMA with addition of the thermal paste. This in turn reduces winding temperature by around $10.5 \%$ at standstill DC tests. The model accuracy has been validated by performing FEA thermal simulations and experimental results.
\end{abstract}

Index Terms - Permanent magnet alternator, lumped parameter (LP) thermal models, thermal analysis, thermal improvements, thermal modelling

\section{INTRODUCTION}

$\mathrm{R}$ eliability, miniaturization and energy efficiency are of primary importance when designing machines for aerospace applications. However, an increased focus on fault tolerance and high performance means thermal behavior is also very important. Arguably, thermal analysis is now as important as electromagnetics in the design procedure for this application. In fact, there is a strong interaction between the electromagnetic and thermal designs as machine losses (copper, iron and friction) are dependent on the temperature variation and vice versa [1]. Any quantified improvement of thermal performance, such as the addition of thermal paste, is hence of value to the machine designer.

The Permanent Magnet Alternator (PMA) in an aerospace engine provides a redundant power supply to the Full Authority Digital Engine Control (FADEC) electronics and actuators; the PMA is directly driven from the engine gearbox, via a dedicated low speed output and must provide constant power across a wide engine speed range [2]. In this paper, the thermal improvement of a PMA by the addition of thermal paste, initially presented in [3], is investigated when mounted on the test bed shown in Fig. 1a.

Finite element analysis (FEA) modelling of the relatively large test bench shown in Fig. $1 \mathrm{~b}(3.15 \mathrm{~m} \times 0.795 \mathrm{~m} \times 0.712 \mathrm{~m})$ would be challenging due to uncertainty of convection heat transfer coefficients of external surfaces, thermal contact conductance (TCC) between test rig parts and thermal properties of the materials. Fig. 1b-d shows the methodology of geometry simplification, as explained in Section VI.

The aim of this paper is to quantify the effect of adding thermal paste to a PMA by calculating principal heat flows, not just observing temperature reduction. To this end, a lumped parameter (LP) thermal model of radial, axial and circumferential heat flow is developed. The validated LP model gives more insight into the effect of thermal paste onto heat flows than either experimental or FEA results as it implies a good understanding of all thermal parameters in the system.

This paper discusses the improvement observed by the addition of thermal paste in sections II and III, before developing and quantifying a lumped parameter thermal model of the system in sections IV and V. More conventional FEA modelling is presented in section VI prior to experimental results in section VII. Finally in sections VIII and IX the quantified validated effect of thermal paste is presented.

\section{Thermal PASTE}

Improvement of heat removal is of primary importance for machine designers as it reduces the hottest temperature spot inside the machine. Increasing average thermal conductivity results in a smaller temperature rise as heat flows more effectively. High thermal conductivity materials such as epoxy resin are usually vacuum impregnated to enhance the thermal path between the winding and the casing [4]-[5]. Alternatively, average machine thermal conductivity can be improved by potting of thermal paste into the machine end region. This provides a thermal contact between the stator and machine housing - effectively opening up a new heat path in the machine.

To investigate this, two PMAs: with and without thermal paste were considered. The machines are identical in terms of rotor, stator and housing structure. The only difference is that a thermal potting material, having a wide operating region between $-50^{\circ} \mathrm{C}$ to $260^{\circ} \mathrm{C}$, 'Silcotherm AS1420' with 1.38 $\mathrm{W} /(\mathrm{mK})$ thermal conductivity was added to end region of the machine to improve the machine cooling, Fig. 2. 

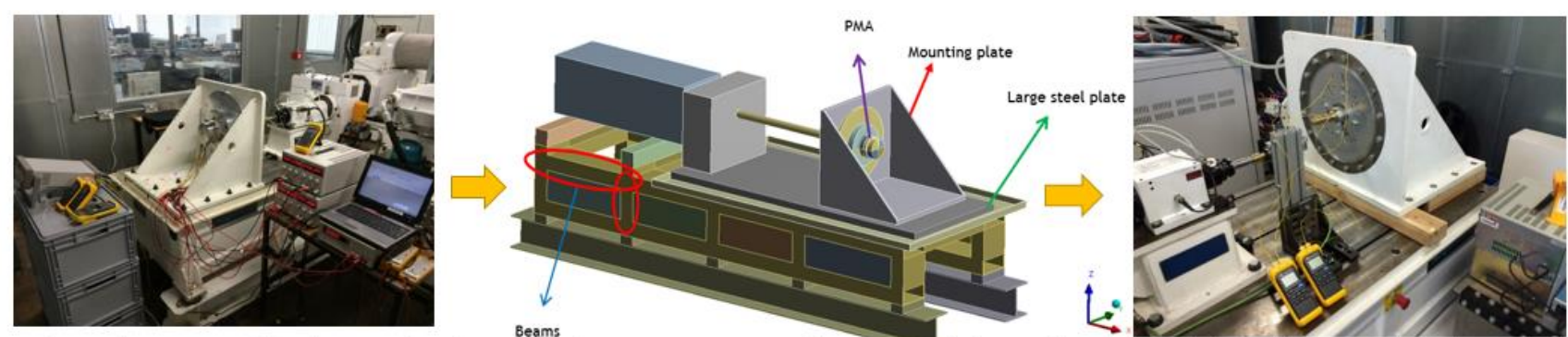

a. Thermal test setup with a large test bench b. Complex FEA geometry of the PMA with the test bench $\mathbf{c}$. Isolation of the PMA from the test bench

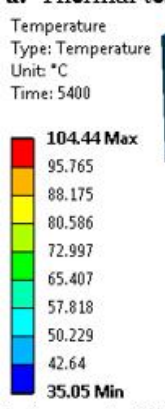

f. A quarter PMA with a thermal boundary

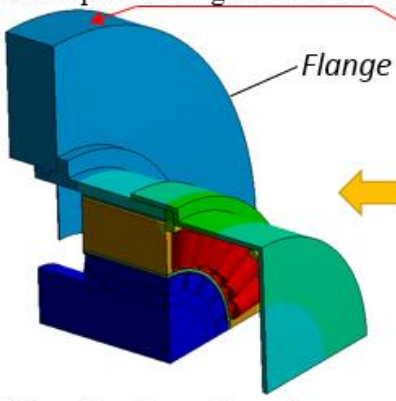

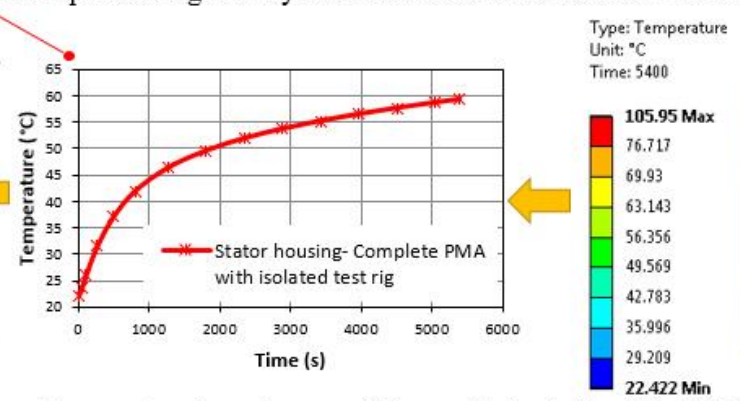

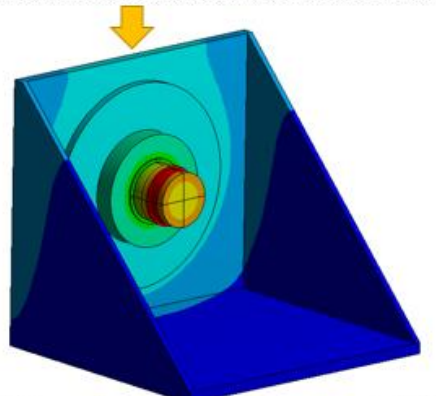

A temperature boundary condition applied d. Simplified FEA thermal model of tlange mounted PMA on top surface of the flange

Fig. 1. A modelling approach developed to simplify the thermal model of the permanent magnet alternator
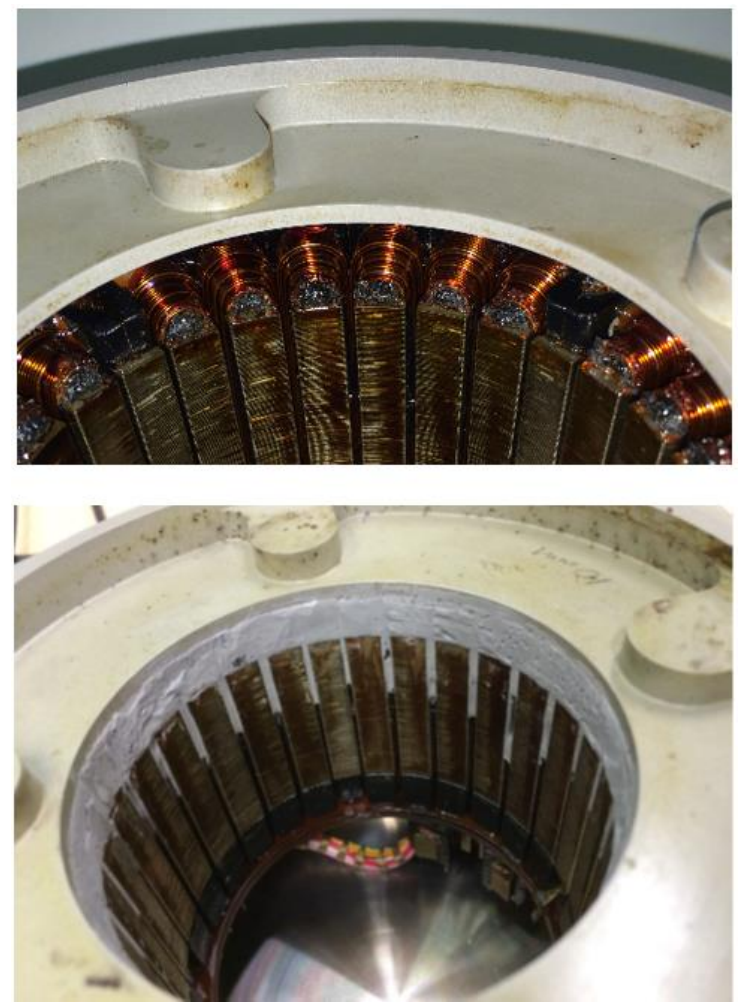

Fig. 2. PMA with (below) and without (above) thermal paste

A steady state thermal test was performed by applying a constant dc current to the stator windings to heat the machine with a known power in the absence of any air circulation inside the machine. 3.5 A dc current was injected to the $Y$-connected power lanes until steady state temperature distribution was obtained around the PMA casing.
Electrical resistance in the windings is monitored to infer average coil temperature rise and understand the accuracy of thermal modelling in the absence of dedicated temperature sensors in the machine windings. During constant current testing, the voltage recordings (1) [6] can be used to predict temperature increase:

$$
T=\left(234.5^{\circ} \mathrm{C}+T_{0}\right) \frac{R_{T}}{R_{0}}-234.5^{\circ} \mathrm{C}
$$

where $T_{0}$ and $T$ are initial and actual temperatures respectively, $R_{T}$ is actual electrical resistance and $R_{0}$ is electrical resistance at reference temperature. $-234.5^{\circ} \mathrm{C}$ is the extrapolated temperature for zero resistance of copper.

In Table I, voltage and current results of $Y$-connected machine terminals clarify the PMA with paste gives a lower temperature rise in the windings. The PMA with thermal paste therefore has a better cooling capability than the PMA without paste. In addition, predicted winding temperature variation in the FEA and LP models can be directly validated by using (1).

TABLE I.

Variation of electrical resistance of the Y-connected winding lanes

\begin{tabular}{|c|c|c|c|c|c|}
\hline $\begin{array}{c}\text { Time } \\
(\mathrm{min})\end{array}$ & $\begin{array}{c}\text { Current } \\
(\mathrm{A})\end{array}$ & $\begin{array}{c}\text { Voltage } \\
(\mathrm{V}) \\
\text { PMA } \\
\text { without } \\
\text { paste }\end{array}$ & $\begin{array}{c}\text { Voltage } \\
(\mathrm{V}) \\
\text { PMA with } \\
\text { paste }\end{array}$ & $\begin{array}{c}\text { Resistance } \\
(\Omega) \\
\text { PMA } \\
\text { without } \\
\text { paste }\end{array}$ & $\begin{array}{c}\text { Resistance } \\
(\Omega) \\
\text { PMA with } \\
\text { paste }\end{array}$ \\
\hline 0. & 3.5 & 11.91 & 11.04 & 3.40 & 3.15 \\
\hline 30. & 3.5 & 15.15 & 13.51 & 4.32 & 3.86 \\
\hline 60. & 3.5 & 15.57 & 13.86 & 4.44 & 3.96 \\
\hline 90. & 3.5 & 15.82 & 14.08 & 4.52 & 4.02 \\
\hline
\end{tabular}

Injected copper loss was calculated at regular time instants during the test. 


\section{Steady State Thermal Tests}

The external surfaces of the PMA were labeled as shown in Fig. 3. The machine was monitored by $K$-type thermocouples to record temperature variation every 5 seconds until reaching steady state.

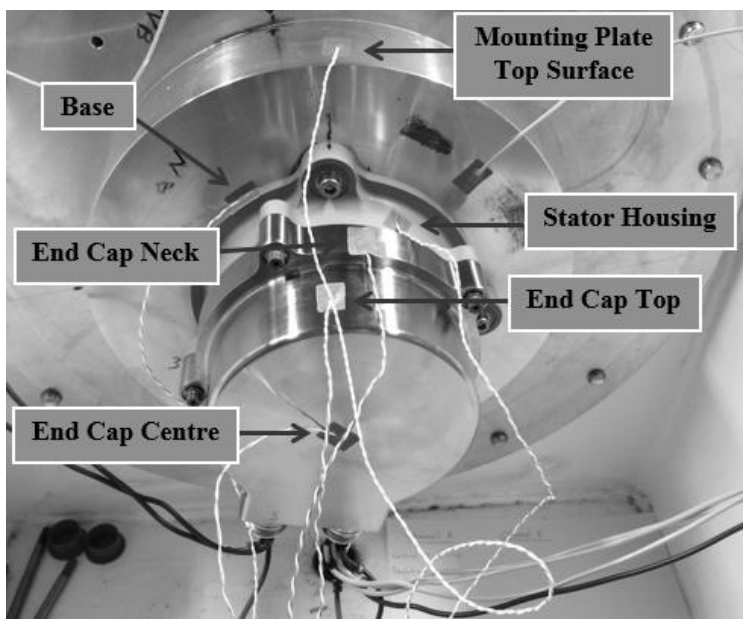

Fig. 3. Labeled PMA external surfaces

In Fig. 4, several experimental temperature variation results are compared for the prototypes with and without thermal paste, again clearly demonstrating that temperature rise for the PMA with thermal paste is lower than that without thermal paste. Nonetheless, pure experimental results cannot be used to actually quantify the heat flow through the new thermal potting. Therefore, the analytical lumped parameter modelling is key to extract heat flow data in the machine components in the presence of thermally conductive paste.
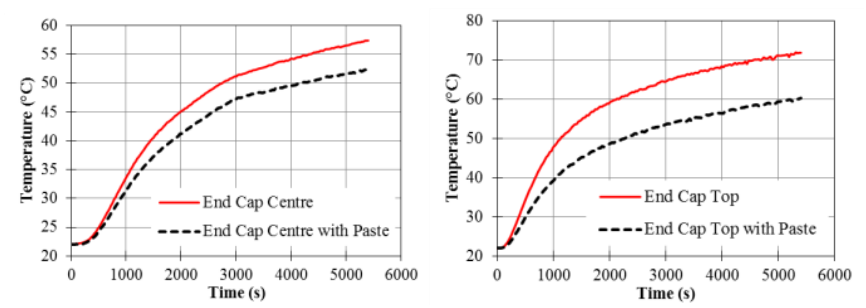

Fig. 4. Temperature rise with and without thermal paste

\section{Thermal Network Modeling}

\section{A. Tooth-slot Lumped Parameter Modelling}

A Lumped Parameter (LP) thermal network was developed to identify the steady state temperatures throughout the PMA including windings, laminations and external casing when only copper losses are injected to the coils. In much thermal network modelling, authors strive to reduce the number of nodes to simplify computation [7]-[8]. Here, the thermal model is implemented in Simulink, which allows many different heat paths to be easily combined. The model incorporates negative compensation thermal resistance, which is represented in Simulink by current controlled voltage source (CCVS). It allows us to take full advantage of Simulink software for this application. Thermal network sub-blocks were used for each significant part of the PMA.

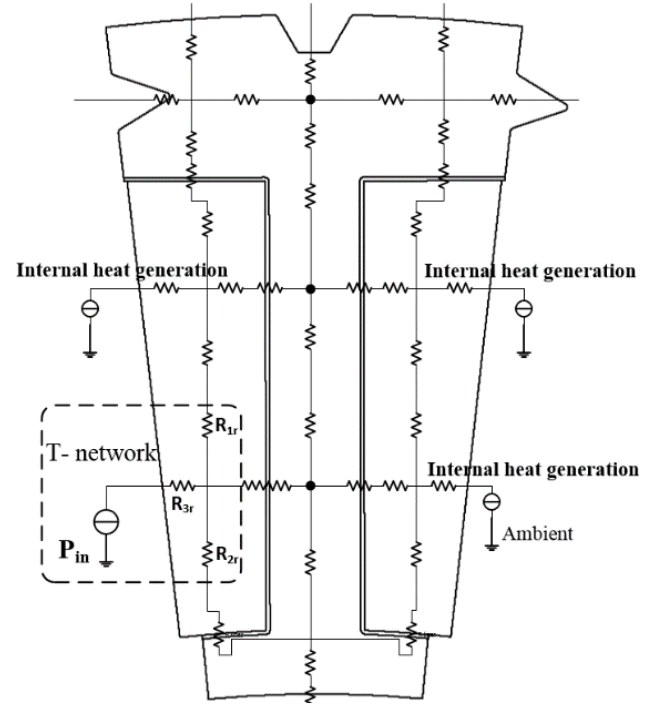

Fig. 5. Tooth - slot equivalent LP model- only radial

For determination of thermal resistances, $T$-equivalent thermal models including radial and axial heat flow were developed. Fig. 5 shows the radial heat flow on the PMA toothslot geometry. A radial flux machine can be simplified to a number of heat generating 2D hollow cylinders with inner and outer radius $r_{1}, r_{2}$, thermal conductivity $k$, and length $L, T$ equivalent thermal circuit is derived from the heat conduction equations [9]. For radial direction:

$$
\begin{gathered}
R_{1 r}=\frac{1}{4 \pi k_{r} L}\left[1-\frac{2 r_{1}{ }^{2} \ln \left(\frac{r_{2}}{r_{1}}\right)}{\left(r_{2}{ }^{2}-r_{1}{ }^{2}\right)}\right] \\
R_{2 r}=\frac{1}{4 \pi k_{r} L}\left[\frac{2 r_{2}{ }^{2} \ln \left(\frac{r_{2}}{r_{1}}\right)}{\left(r_{2}{ }^{2}-r_{1}{ }^{2}\right)}-1\right] \\
R_{3 r}=\frac{-1}{8 \pi k_{r} L\left(r_{2}{ }^{2}-r_{1}^{2}\right)}\left[r_{2}{ }^{2}+r_{1}{ }^{2}-\frac{4 r_{1}{ }^{2} r_{2}{ }^{2} \ln \left(\frac{r_{2}}{r_{1}}\right)}{r_{2}{ }^{2}-r_{1}{ }^{2}}\right]
\end{gathered}
$$

For axial direction:

$$
\begin{aligned}
& R_{1 a}=\frac{L}{2 \pi k_{a}\left(r_{2}{ }^{2}-r_{1}{ }^{2}\right)} \\
& R_{2 a}=\frac{L}{2 \pi k_{a}\left(r_{2}{ }^{2}-r_{1}{ }^{2}\right)} \\
& R_{3 a}=\frac{-L}{6 \pi k_{a}\left(r_{2}{ }^{2}-r_{1}{ }^{2}\right)}
\end{aligned}
$$

Note that $R_{3 r}$ and $R_{3 a}$ in (4) and (7) are negative thermal resistances. They are hence modeled as current controlled voltage sources to obtain a compensation resistance for thermal modelling of the slot. The thermal network sub-block for a single tooth-slot pair is depicted in Fig. 6 .

In Fig. 8 (discussed in section VIII, later), the overall thermal lumped parameter model consisting of the tooth-slot sub-blocks as depicted in Fig. 6 is shown. As with the FEA 
model, the thermal network is developed for a quarter of the PMA with a part of the aluminum mounting plate, 6 single tooth windings and two spacer teeth. Each single tooth winding has radial, axial and circumferential heat flows. For the PMA without thermal paste, axial heat flow will not be significant as the machine is axially short $(40 \mathrm{~mm})$ and the end winding is not a significant part of the stator winding (End winding radius $\approx 4.62 \mathrm{~mm}$ ). The machine does not have any dedicated cooling system so the main heat paths in the machine are in the radial direction rather than axial.

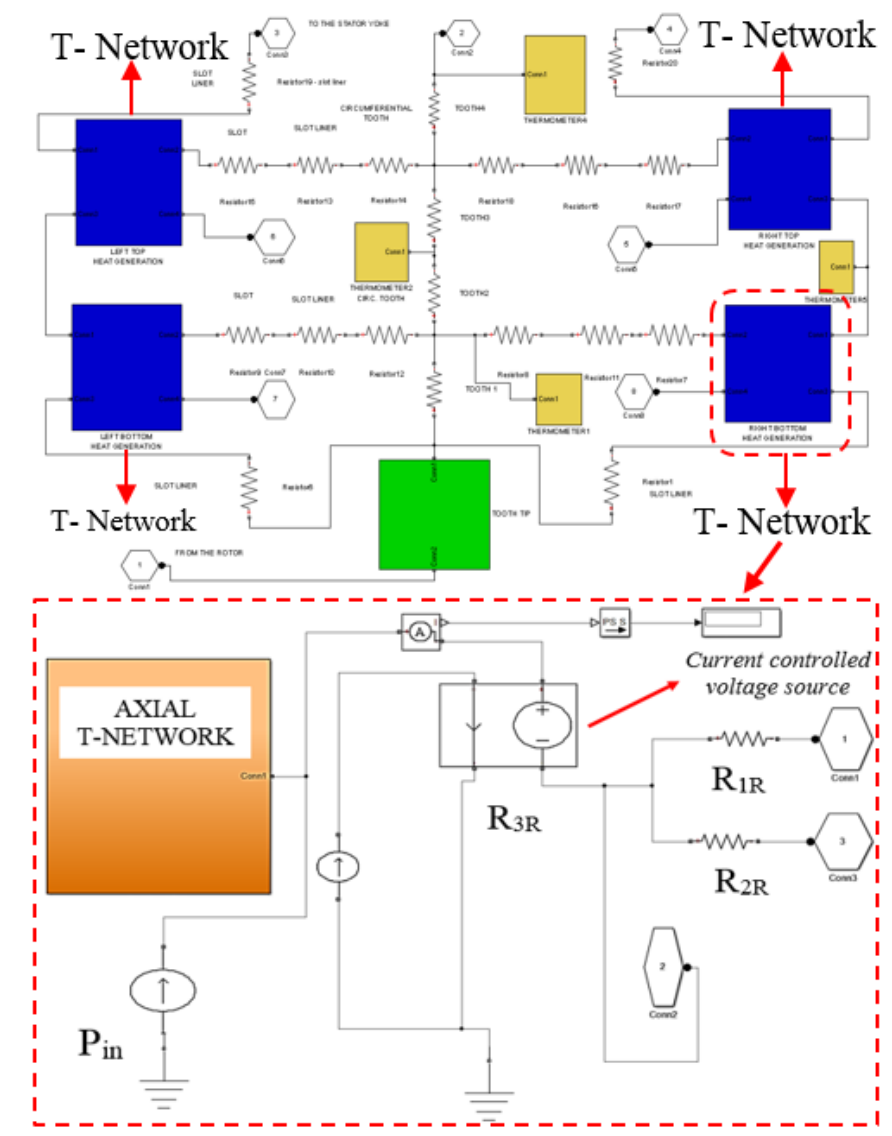

Fig. 6. Simulink tooth-slot sub-block

\section{B. End Winding Lumped Parameter Modelling}

The stator end windings are divided into discrete layers, as their trapezoidal shape forms a number of half hollow cylinders with a certain thickness. Assuming heat flows into the paste through the top of the end windings, as depicted in Fig. 7, the half hollow cylinder shape winding segments can be divided into two parts. Each part forms a quarter hollow cylinder with a circumferential thermal resistance of $R_{e w}$ where the heat is assumed to flow only in the $\theta$ direction. Thermal boundary conditions are set as $T_{1}$ and $T_{2}$ at $\theta_{1}=0$ and $\theta_{2}=\pi / 2$ respectively as shown in Fig. 7 .

The end windings of the PMA is divided into two layers due to their small radius. Each layer consists of quarter hollow cylinders with a thermal resistance: $R_{e w}$.
For steady state heat flow without heat generation in the end windings (i.e. assuming that all heat is generated in the center of the slot), the net conducted heat can be obtained by solving the general heat equation in cylindrical coordinates [10] for a quarter hollow cylinder with temperature boundary conditions: $T_{1}$ and $T_{2}$. Heat flow $(Q)$ can be obtained for the upper quarter layer with a thickness of $t_{1}$ in Fig. 7 as given in (8):

$$
Q=\frac{2 k}{\pi} \cdot \ln \frac{r_{b}}{r_{a}} \cdot\left[T_{1}-T_{2}\right] t_{1}
$$

where $k$ is the end winding axial thermal conductivity estimated at $10 \%$ less than the copper isotropic thermal conductivity and the radiuses $r_{a}$ and $r_{b}$ are shown in Fig. 7 . By using the equation of thermal resistance for conduction, the thermal resistance, $R_{e w}$ in the $\theta$ direction can be written:

$$
R_{e w}=\frac{\pi / 2}{\ln \left(\frac{r_{b}}{r_{a}}\right) k t_{1}}
$$

$R_{e w}$ is only half of the end winding layers and each half of the winding layers are in parallel. Each $R_{e w}$ value can be computed using geometrical dimensions of the end windings. Thus, the equivalent thermal resistance of each PMA end winding, when only a 2-layer system is considered, is found to be $0.654{ }^{\circ} \mathrm{C} / \mathrm{W}$. The significance of end winding thermal resistance is usually dependent upon machine size.

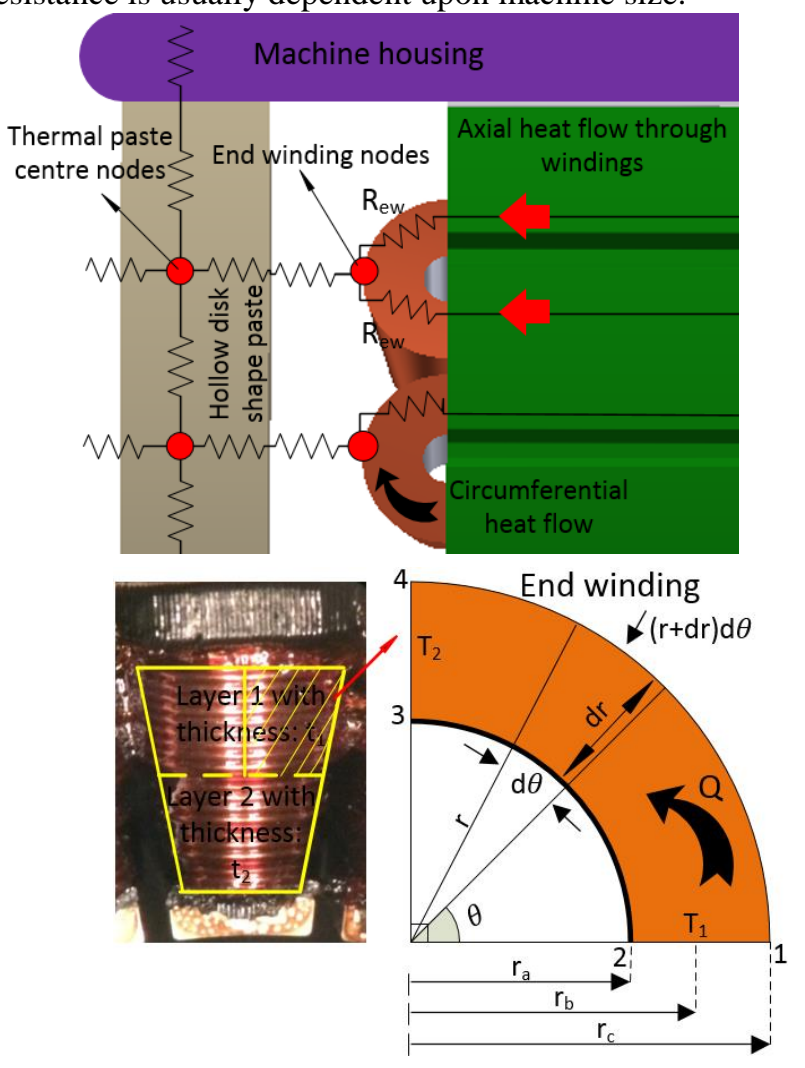

Fig. 7. Discretization of stator end windings 


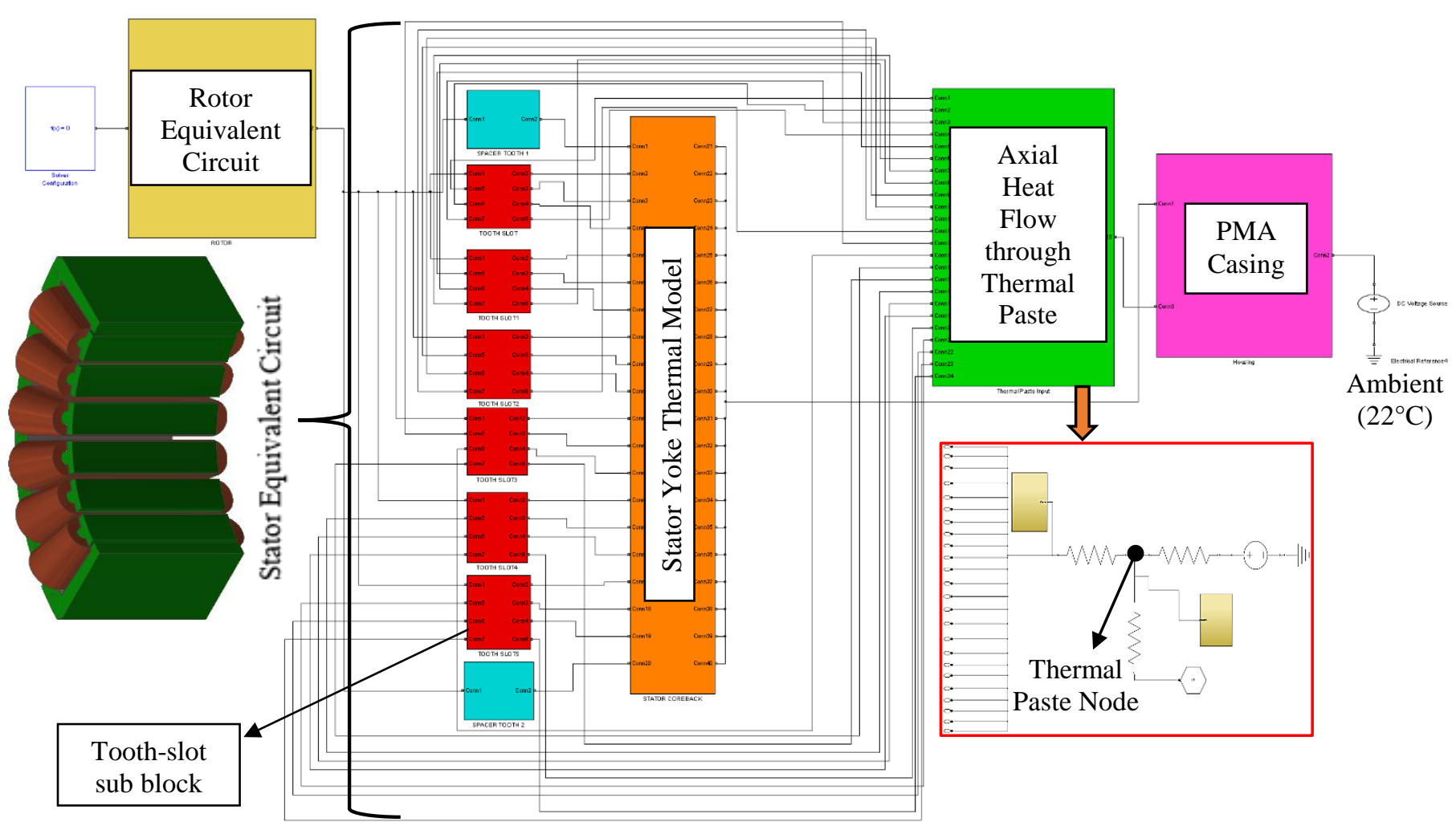

Fig. 8. Developed thermal lumped parameter model for the quarter PMA with thermal paste

TABLE II.

Computed thermal lumped parameters of the PMA with paste

\begin{tabular}{|c|c|}
\hline Parameter (radial and axial) & $P M A$ with paste \\
\hline$R_{1 r-\text { copper }}$ & $0.039^{\circ} \mathrm{C} / \mathrm{W}$ \\
\hline$R_{2 r-\text { copper }}$ & $0.043^{\circ} \mathrm{C} / \mathrm{W}$ \\
\hline$R_{3 r-\text { copper }}$ & $-0.014^{\circ} \mathrm{C} / \mathrm{W}$ \\
\hline$R_{1 a-\text { copper }}$ & $468.4^{\circ} \mathrm{C} / \mathrm{W}$ \\
\hline$R_{2 a-\text { copper }}$ & $1.116^{\circ} \mathrm{C} / \mathrm{W}$ \\
\hline$R_{3 a-\text { copper }}$ & $-0.372^{\circ} \mathrm{C} / \mathrm{W}$ \\
\hline$R_{\text {equivalent insulation }}$ & $1.719^{\circ} \mathrm{C} / \mathrm{W}$ \\
\hline
\end{tabular}

In Table II, a summary of important T-network thermal lumped parameters dependent upon the stator slot geometry and dimensions is given. The significant parameter is axial thermal resistance, $R_{1 a-c o p p e r}$ which is an equivalent resistance between the slot center and the un-potted stator end windings.

\section{THERMAL PARAMETER DETERMINATION}

\section{A. Identification of Heat Transfer Coefficients}

There are three types of external surface in the PMA: vertical plane, horizontal plane and horizontal cylinder for natural convection between the ambient surroundings and the PMA. Since there is no external cooling in the laboratory, only natural convection needs to be considered. Temperature dependent empirical heat transfer coefficients are used [11]-
[12] for the external horizontal and cylindrical surfaces as plotted in Fig. 9, below.

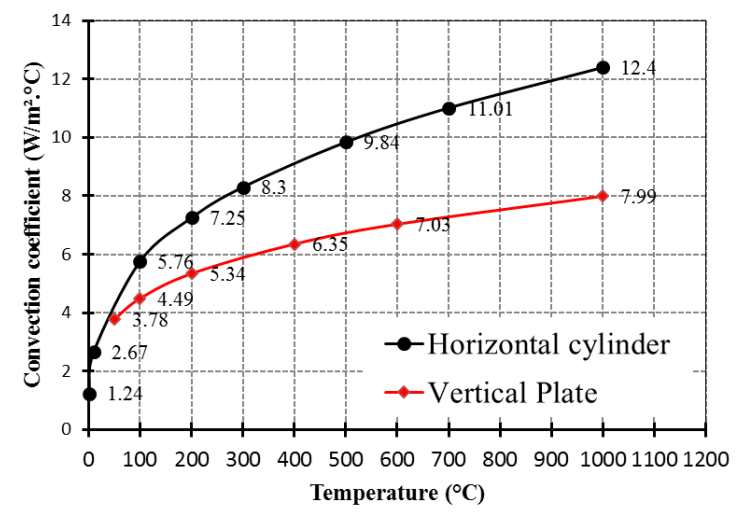

Fig. 9. Temperature dependent heat transfer coefficients

Since thermal modeling is performed for the stationary PMA, speed dependent heat transfer coefficients as proposed in [13]-[14] such as rotor, internal air and end winding convections will not be significant. The rotor of the PMA was taken as a horizontal cylinder for which temperature dependent heat transfer coefficients are given in Fig. 9. The convection heat transfer coefficient between stator winding external connections and inner air can be evaluated as proposed in [15]:

$$
h_{e w}=6.5+5.25^{0.6} u_{r}^{0.6}
$$

where $u_{r}$ is the rotor peripheral velocity. As the mounting plate also has a horizontal plate at the bottom, natural convection 
from a horizontal plate can be predicted using the equations [10]:

$$
\begin{gathered}
N u=\frac{h L}{k}, \quad \operatorname{Pr}=\frac{\mu C_{p}}{k} \\
R a=G r \operatorname{Pr}
\end{gathered}
$$

$$
G r=\left[\frac{L^{3} \rho^{2} g \Delta T \beta}{\mu^{2}}\right]
$$

$$
\begin{array}{lll}
\text { For upper } & N u=0.54 R a^{1 / 4} & \left(10^{4} \leq R a \leq 10^{7}\right) \\
\text { surface: } & N u=0.15 R a^{1 / 3} & \left(10^{7} \leq R a \leq 10^{11}\right)
\end{array}
$$

For lower surface:

$$
N u=0.27 R a^{1 / 4} \quad\left(10^{5} \leq R a \leq 10^{10}\right)
$$

Dimensionless $\mathrm{Nu}, \mathrm{Pr}$ and $\mathrm{Gr}$ numbers are used to calculate natural heat transfer coefficients. $\mu, C_{p}, k$ denote fluid viscosity $\left(\mathrm{Ns} / \mathrm{m}^{2}\right)$, fluid specific heat $\left(J / g^{\circ} K\right)$ and fluid thermal conductivity $(W / m K)$ respectively. $\rho, g$ and $\beta$ stand for fluid density $\left(\mathrm{kg} / \mathrm{m}^{3}\right)$, gravity and fluid thermal expansion coefficient $\left({ }^{\circ} \mathrm{K}^{-1}\right)$ respectively. The definition of length parameter is given as: $L=$ area of plate / perimeter of plate. Correlations of $N u$ number for upper and lower surfaces are calculated using $R a$ numbers at given intervals. Heat transfer coefficients were calculated for upper surface: $6.96 \mathrm{~W} / \mathrm{m}^{2} .{ }^{\circ} \mathrm{C}$ and for lower surface $1.76 \mathrm{~W} / \mathrm{m}^{2} .{ }^{\circ} \mathrm{C}$ when the fluid is stagnant air at ambient temperature $\left(22^{\circ} \mathrm{C}\right)$.

\section{B. Model Implementation}

The implementation of LP model and 3-D FEA simulations requires identification of the machine dimensions, material properties and the thermal uncertainties [16] of the machine sub-assemblies. The key dimensions in the 3-D model are shown in Fig. 10.

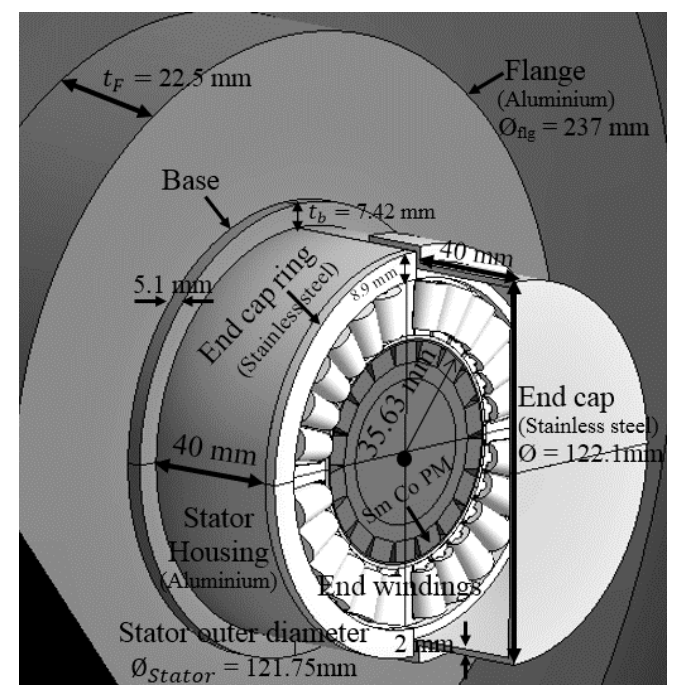

Fig. 10. 3-D complete model of the PMA
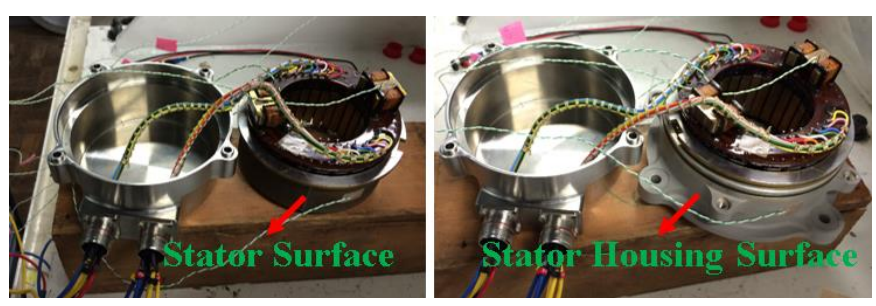

Fig. 11. Thermal test setup to estimate TCC between the stator and housing: without housing (left); with housing (right)

The critical thermal resistances (i.e. housing lamination interference gap, effective winding model and thermal contact between the housing parts) have been identified by thermal calibration requiring 3-D FEA simulations and sub-models of the LP network. The calibration is performed by modifying the values within a typical range until responses of steady state DC thermal tests and the complete FEA model results match. The calibration of thermal models has been conducted for both the complete machine prototype and the sub-assemblies such as stator-housing, as shown in Fig.11.

The effective thermal conductivity of the stator windings was estimated using effective average distribution of materials in the slot. To simplify the 3-D FEA model, equivalent insulation of the winding is assumed to be a barrier between the bulk copper and the slot wall as proposed in [17]-[18]. Thermal resistances are predicted in the sub-LP models.

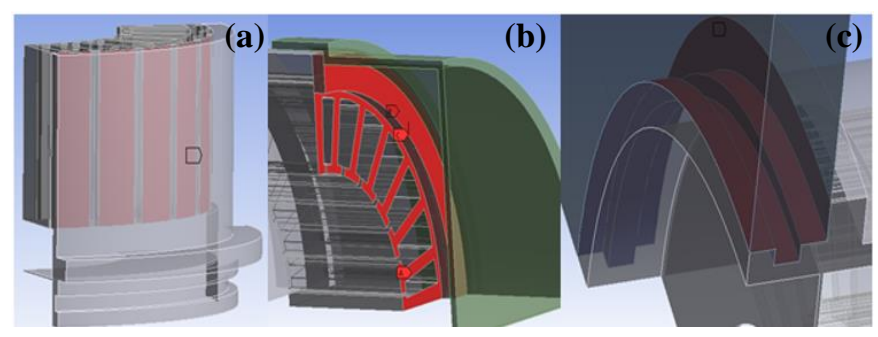

Fig. 12. Thermal contact regions shown red: (a) stator core to housing; (b) stator to end cap ring; (c) housing to flange

In Fig. 12, important thermal contact regions in the PMA assembly are shown. Thermal properties of the materials are given in [3]. In [19], interfacial conductance and interface gap of the metals are tabulated. Thermal contact conductance between stainless steel and aluminum varies between $3000-$ $4500 \mathrm{~W} / \mathrm{m}^{2} .{ }^{\circ} \mathrm{C}$ for an effective gap in the range $0.0058-0.0087 \mathrm{~mm}$. During the thermal calibration process, it was noted that thermal contact conductance between the stainless steel end casing and aluminum housing is around $1500 \mathrm{~W} / \mathrm{m}^{2} .{ }^{\circ} \mathrm{C}$. This implies that there is not a perfect thermal contact between the machine housing parts. However, varying the thermal contact conductance between the stator housing and end casing in the range $1000 \mathrm{~W} / \mathrm{m}^{2} .{ }^{\circ} \mathrm{C}$ - $3000 \mathrm{~W} / \mathrm{m}^{2}$. ${ }^{\circ} \mathrm{C}$ changes the temperature variation on the machine casing in the range $1^{\circ} \mathrm{C}-3^{\circ} \mathrm{C}$. This is not thought to be a significant temperature difference to cause a substantial temperature distribution error. The temperature drop between two contact surfaces is of the form [20]: 


$$
R_{\text {contact }}=\frac{1}{h_{\text {cont }} \cdot A}
$$

where, $h_{\text {cont }}$ is the contact coefficient and $A$ is the surface area of the contact. The estimated thermal parameters for the complete model of the PMA are summarized in Table III.

TABLE III.

Estimated important thermal parameters of the PMA

\begin{tabular}{|c|c|}
\hline Parameters to be estimated & Value \\
\hline Effective slot thermal conductivity & $0.15 \mathrm{~W} /(\mathrm{m} . \mathrm{K})$ \\
\hline Stator core to housing TCC (Fig. 11$)$ & $390 \mathrm{~W} /\left(\mathrm{m}^{2} . \mathrm{K}\right)$ \\
\hline Stator core to end cap ring TCC & $4000 \mathrm{~W} /\left(\mathrm{m}^{2} . \mathrm{K}\right)$ \\
\hline Housing to flange TCC & $600 \mathrm{~W} /\left(\mathrm{m}^{2} . \mathrm{K}\right)$ \\
\hline End cap to housing TCC & $1500 \mathrm{~W} /\left(\mathrm{m}^{2} . \mathrm{K}\right)$ \\
\hline
\end{tabular}

\section{3-D THERMAL FEA MODELLING}

Due to symmetry of the geometry, both the analytical LP model and the FEA models consider a quarter of the PMA to reduce the computation cost of the full 3-D FEA model given in Fig. 13.

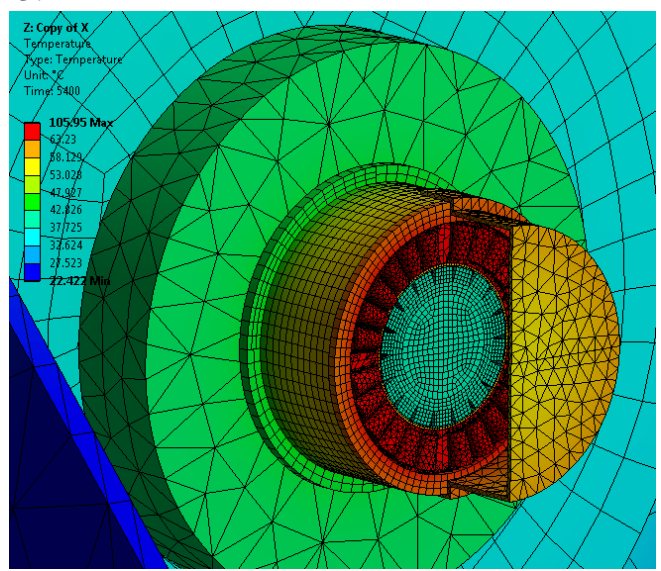

Fig. 13. A complete 3D FEA model of the PMA

In Fig. 1d-f, simplification of the FE model is shown. The accuracy of the simplification is investigated by performing transient thermal FEA simulations. In Fig. 14, temperature variations around the machine casing and stator for the full and one quarter models are very close, with less than a 5\% temperature error. This gives confidence that, with proper boundary conditions, the one quarter model can be used to calculate the amount of heat flow through the paste.
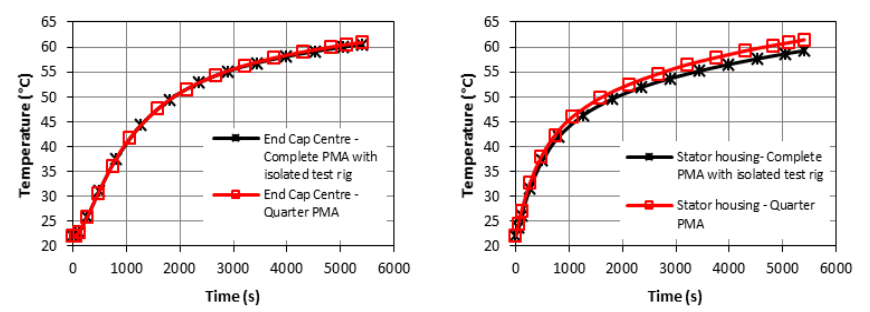

Fig. 14. Comparison of temperature variations for the PMA external surfaces

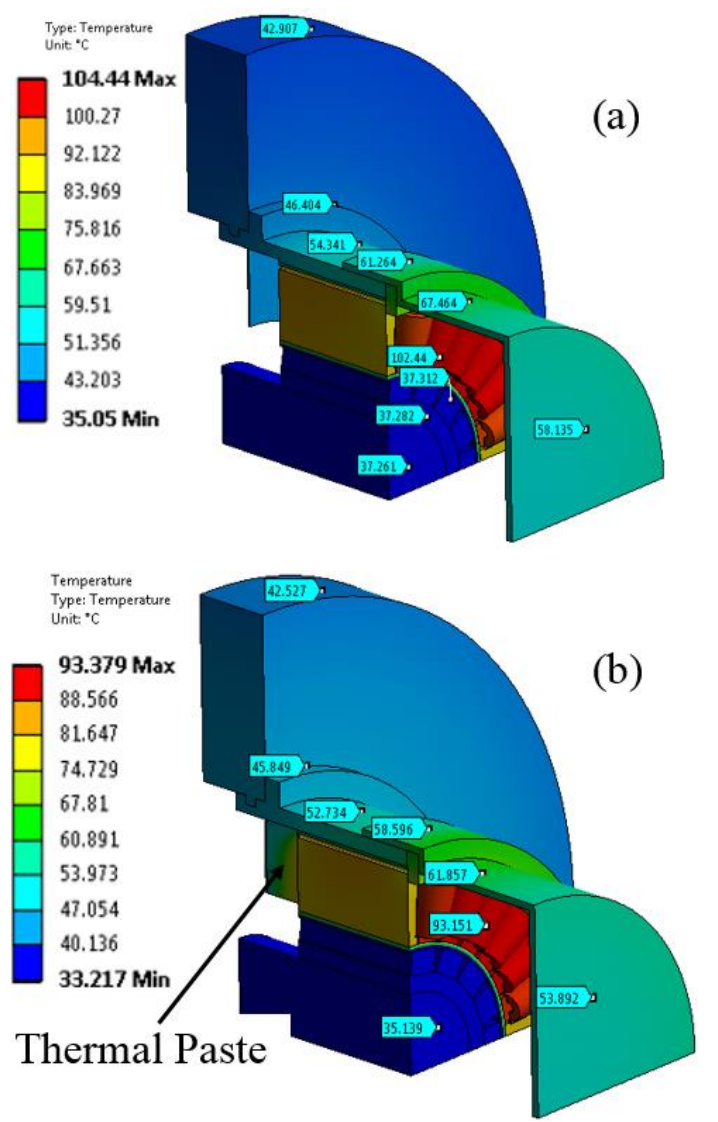

Fig. 15. FEA results at steady state for the prototypes: PMA (a) without thermal paste; (b) with thermal paste

Calibrated thermal FEA results at steady state when only copper losses are injected are given in Fig. 15. Thermal FEA simulation results show that the hottest spot temperature in the winding is reduced by $10.6 \%$ and the SmCo permanent magnet temperature is reduced by around $2^{\circ} \mathrm{C}$ at standstill. Radial temperature variation starting from the shaft center to ambient is plotted in Fig. 16 using FEA results, showing that temperature rise in the machine windings is significantly affected by the addition of thermally conductive paste.

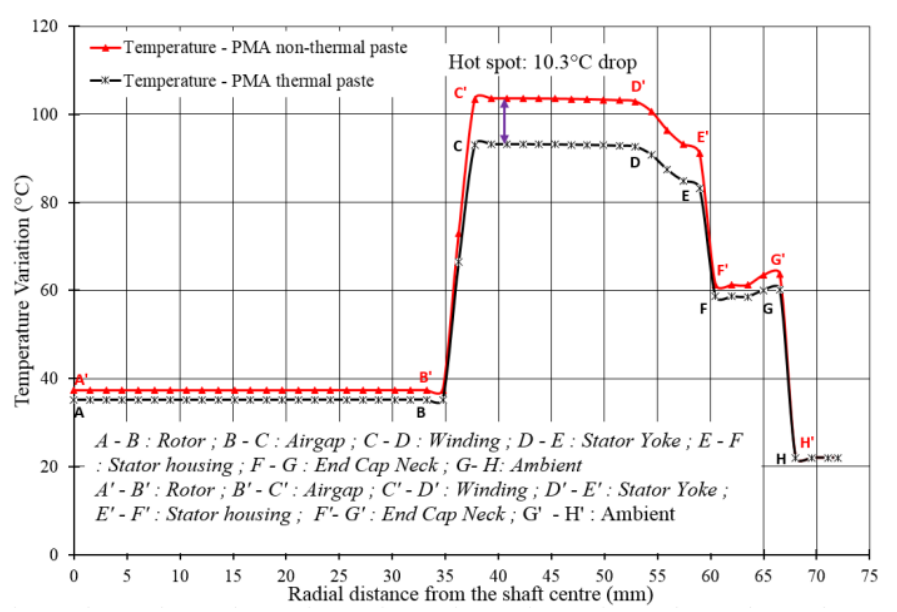

Fig. 16. Radial temperature variation around the PMAs 


\section{EXPERIMENTAL VALIDATION OF MODELS}

In order to demonstrate the accuracy of analytical and FEA thermal models for the prototype machine with thermal paste, a comparison table with relative error between the modelling methods is shown in Table IV.

TABLE IV.

Steady state temperature results and relative error comparison for the prototype with thermal paste

\begin{tabular}{|c|c|c|c|c|c|}
\hline Part & $\begin{array}{c}\text { Thermal } \\
\text { Lumped } \\
\left({ }^{\circ} \mathbf{C}\right)\end{array}$ & $\begin{array}{c}\text { Thermal } \\
\text { FEA } \\
\left({ }^{\circ} \mathbf{C}\right)\end{array}$ & $\begin{array}{c}\text { Experiment } \\
\left({ }^{\circ} \mathbf{C}\right)\end{array}$ & $\begin{array}{c}\text { Error } \\
(\%) \\
\text { FEA-LP }\end{array}$ & $\begin{array}{c}\text { Error } \\
(\%) \\
\text { Experiment- } \\
\text { LP }\end{array}$ \\
\hline Shaft & 35.74 & 35.13 & 36.5 & 1.70 & -2.12 \\
\hline $\begin{array}{c}\text { Rotor } \\
\text { core } \\
\text { back }\end{array}$ & 35.74 & 35.15 & - & 1.65 & - \\
\hline Magnets & 35.74 & 35.17 & - & 1.59 & - \\
\hline Tooth tip & 88.92 & 89.27 & - & -0.39 & - \\
\hline $\begin{array}{c}\text { Tooth } \\
\text { centre }\end{array}$ & 89.07 & 89.54 & - & -0.52 & - \\
\hline $\begin{array}{c}\text { Spacer } \\
\text { tooth }\end{array}$ & 84.13 & 81.04 & - & 3.67 & - \\
\hline Winding & 90.05 & 91.68 & - & -1.81 & - \\
\hline $\begin{array}{c}\text { Stator } \\
\text { core } \\
\text { back }\end{array}$ & 78.41 & 78.22 & - & 0.24 & - \\
\hline $\begin{array}{c}\text { End cap } \\
\text { centre }\end{array}$ & 55.03 & 53.89 & 56.67 & 2.07 & -2.98 \\
\hline $\begin{array}{c}\text { End cap } \\
\text { top }\end{array}$ & 61.82 & 61.85 & 63.18 & -0.04 & -2.19 \\
\hline $\begin{array}{c}\text { End cap } \\
\text { neck }\end{array}$ & 55.60 & 57.03 & 59.49 & -2.57 & -6.99 \\
\hline $\begin{array}{c}\text { Stator } \\
\text { housing }\end{array}$ & 54.89 & 53.59 & 52.20 & 2.36 & 4.90 \\
\hline Base & 46.09 & 46.30 & 46.68 & -0.45 & -1.28 \\
\hline
\end{tabular}

As shown in Table IV, the relative error between the FEA simulations and lumped parameter model is $3.6 \%$. Also, the error between thermal lumped model and experimental results is $7 \%$. It can be noted that no measurements were taken inside the prototype machine for these tests as there is no access to machine stator and windings. Nonetheless, measurements taken from the steady state thermal tests are adequate to quantify the amount of heat flow through the thermal paste by taking axial heat flow into account in thermal lumped model for the PMA with thermal paste.

\section{INVESTIGATION THE EFFECT OF THERMAL PASTE ON MACHINE THERMAL PERFORMANCE}

\section{A. Computation of Heat Flow through the Paste}

When temperature change $(\Delta T)$ is compared for the test results, the prototype with thermal paste gives a $14.8 \%$ lower temperature rise on the external surfaces of the machine and mounting plate.
When a thermal paste is added to the single side of the stator end region, axial heat flow becomes a more significant part of the total heat flow inside the machine. In this case, the axial heat flow component is as important as the radial heat component. In the thermal lumped parameter model, this is a new conductive heat path, shown as green sub-block in Fig. 8.

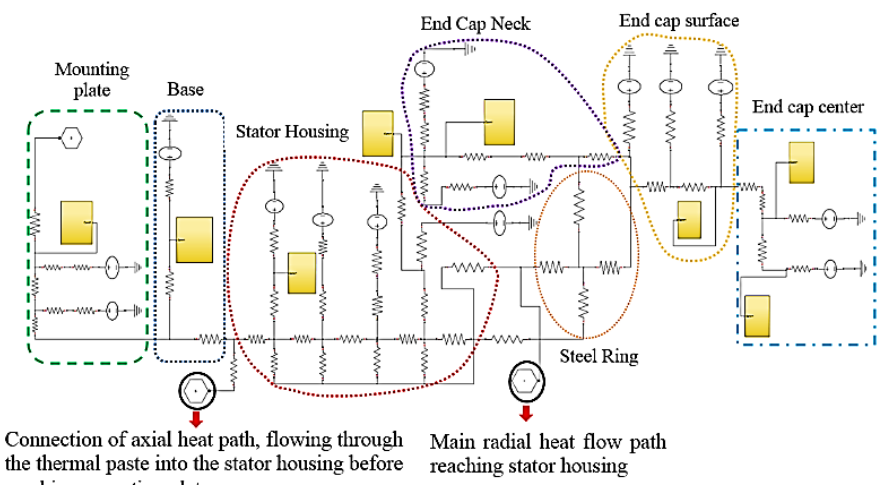
the thermal paste into the stator housing before reaching stator housing reaching mounting plate

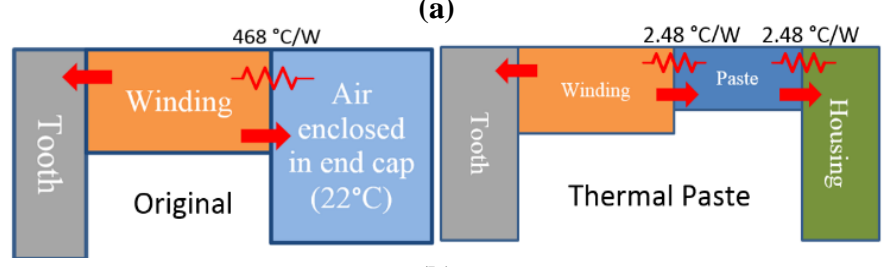

(b)

Fig. 17. (a) Simplified thermal network for the PMA frame; (b) Equivalent thermal circuit representation of axial flow of end winding

Fig. 17 shows a simplified extract of the LP model. Replacing the end winding convection in the original PMA with conduction through the thermal paste, the new thermal path is seen to reduce the thermal resistance by around one hundredth. For a quarter of the machine with and without thermal paste, Table $\mathrm{V}$ shows significant heat flows when maximum DC copper loss is injected to the coils.

TABLE V.

Main heat paths around the PMA with thermal paste

\begin{tabular}{|c|c|c|c|}
\hline $\begin{array}{c}\text { Rate of Heat Flow, Watts } \\
\text { (Joules per second) }\end{array}$ & $\begin{array}{c}\text { PMA } \\
\text { with } \\
\text { paste }\end{array}$ & $\begin{array}{c}\text { PMA } \\
\text { without } \\
\text { paste }\end{array}$ & Unit \\
\hline Total & 49.28 & 55.3 & Watts \\
\hline Radial & 36.88 & 44.33 & Watts \\
\hline Axial & 9.89 & 7.97 & Watts \\
\hline Rotor heat flow & 2.36 & 3.02 & Watts \\
\hline Heat flow through thermal paste & 6.847 & - & Watts \\
\hline
\end{tabular}

As tabulated in Table $\mathrm{V}$, radial heat flow constitutes a significant part of the total heat flow $(80.2 \%)$ for the PMA without thermal paste, as axial heat flow occurs only due to heat transfer by convection. Axial heat flow has been improved 
for the PMA with thermal paste. When $14.4 \%$ of the total generated heat flows axially for the prototype machine with paste, this has been increased to $20 \%$ by adding thermal paste. Therefore, the improvement in average thermal resistance of the PMA machine by adding thermal paste can be quantified as $468^{\circ} \mathrm{C} / \mathrm{W}$ to $4.96^{\circ} \mathrm{C} / \mathrm{W}$.

\section{Dynamic Thermal Tests Performance COMParison}

\section{A. No Load Thermal Tests at Rated Speed}

Accurate thermal modelling of the alternator at rated speed, on no load condition requires accurate prediction of core losses. To provide a relationship between the temperature rise and core losses, known DC currents (2.5 A and 3.5 A) were applied to stator windings for 100 minutes. Temperature was measured at the 'Base' of the PMA as depicted in Fig. 3. Then, temperature was measured during a $100 \%$ speed 100 minutes open circuit test. The test was repeated with the rotor in air by removing the stator housing - the no-stator test - where rise in temperature was assumed to be due to bearing loss alone. Known power losses at different DC current ratings can be used to estimate the stator iron losses by employing linear extrapolation as shown in Fig. 18. As the temperature rise at 'Base' of the PMA is determined for the open circuit test, total core stator core losses can be deduced as previously reported by the authors in [21].

For the PMA with and without thermal paste, the core losses are 417 Watts and 433 Watts, respectively. Although the prototype alternators are identical in terms of stator core material, there is a slight difference in the core losses perhaps due to segmented core manufacturing. For 3D-FEA simulations, however, an average of 425 Watts of power loss was injected to the stator cores to quantify the effect of thermal paste when the machines are open circuit and spinning at rated speed, $14820 \mathrm{rpm}$ for 100 minutes.

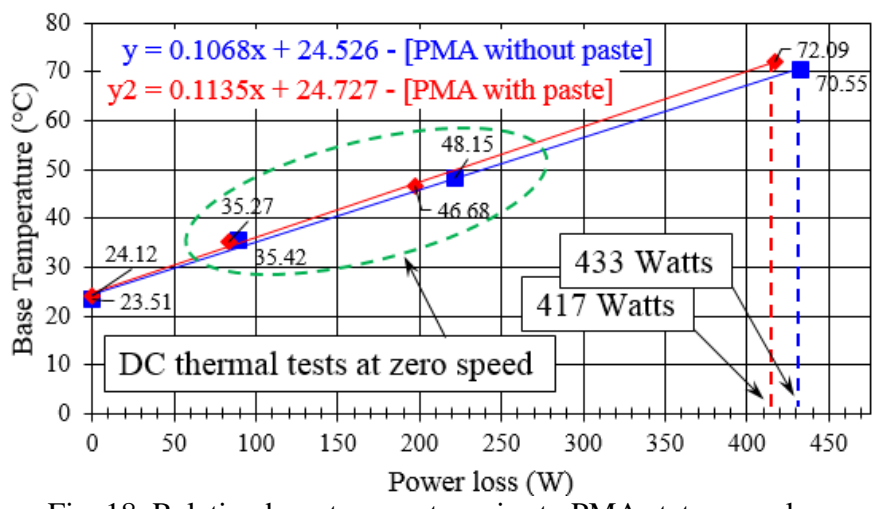

Fig. 18. Relating base temperature rise to PMA stator core loss

Fig.19 shows calibrated 3D-FEA results of the PMAs with and without thermal paste and it is proved that the stator windings in the PMA with paste stay about $22^{\circ} \mathrm{C}$ cooler than the PMA without thermal paste as plotted in Fig. 20.

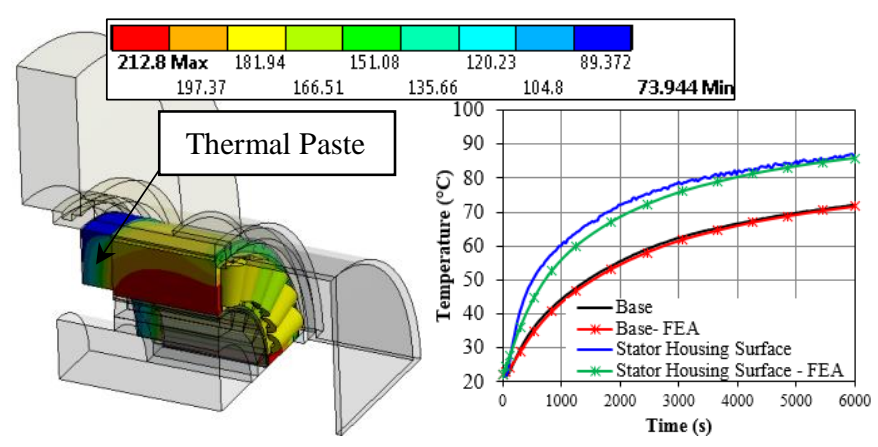

(a)

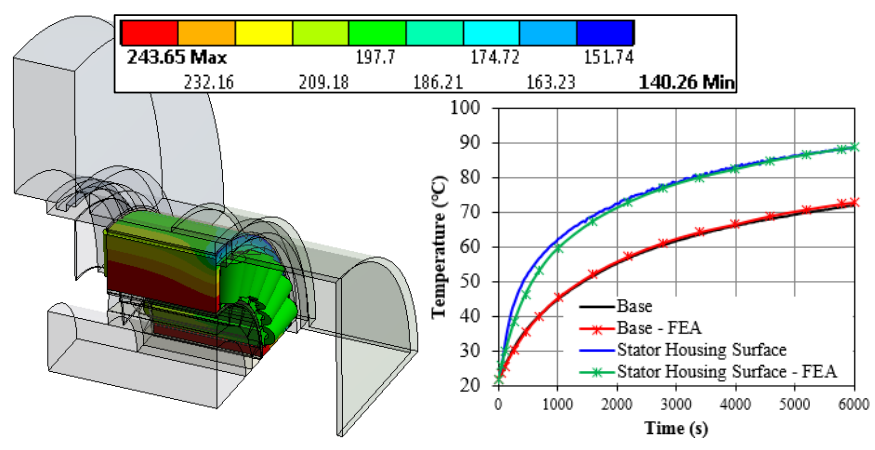

(b)

Fig. 19. PMA: (a) with thermal paste at rated speed on-no load, 3DFEA, (b) without thermal paste at rated speed on-no load, 3D-FEA

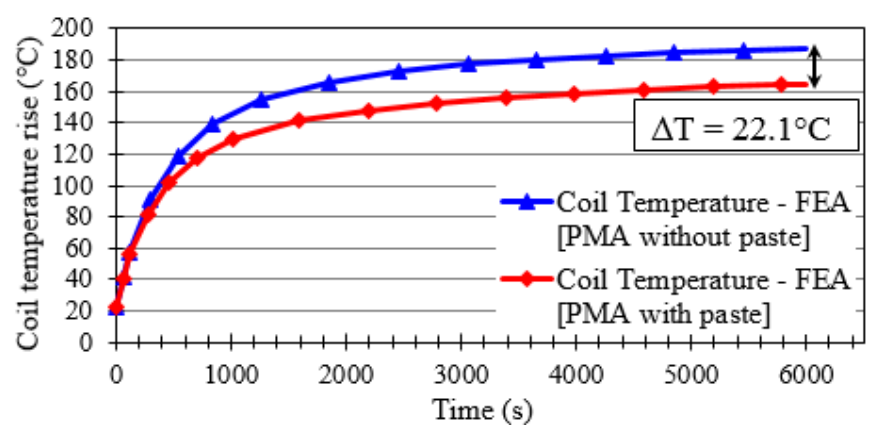

Fig. 20. PMA: Temperature rise in a complete coil at rated speed on no load, 3D-FEA

\section{B. Short Circuit Thermal Test Results at Rated Speed for the PMAs with open end - Experimental Only}

There is no ad-hoc temperature sensor in the end windings of the prototype PMAs. The machine end cap was left open and a number of thermal tests have been conducted at different speeds to measure the temperature directly in the end windings as shown in Fig. 21. In this case, FEA or LP models were not employed due to significant variations in the machine loss characteristics and the fluid (i.e. air) behavior around the machine open end.

All power lanes are short circuited when the machine is at rated speed to investigate the effect of both $\mathrm{AC}$ and DC copper losses on the thermal performance of the machines with and without the potting material. The RMS phase current is limited 
to 2.44 A over a wide speed range ( $2000 \mathrm{rpm}-15000 \mathrm{rpm})$ in line with the operating requirements of this design [2].

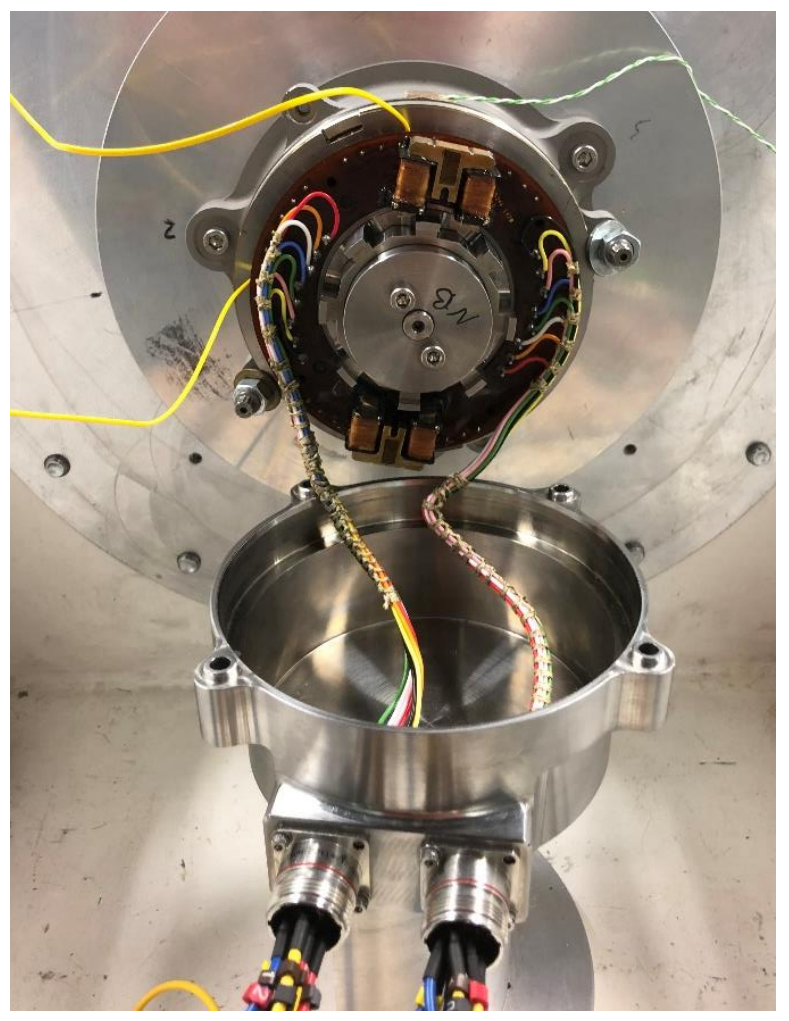

Fig. 21. Open Endcap PMA with $2.44 A_{r m s}$ short circuit current

The stator of the PMAs generate heat due to active core and copper (AC and DC) losses while running at different speeds. The experimental temperature rise at steady state in the end windings of the PMAs is obtained as given in Fig. 22. It is demonstrated that the PMA with thermal paste exhibits a better thermal performance due to lower temperatures in the coils, providing an improved life expectancy in this machine.

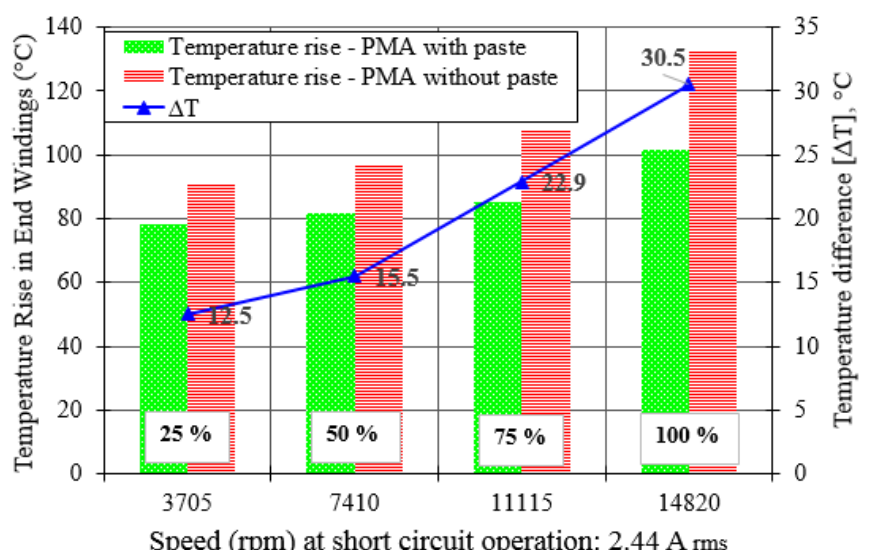

Fig. 22. Temperature rise in end windings at different speeds

\section{CONCLUSION}

In this work, a thermal test procedure has been presented for PMAs with and without thermal paste. FEA and lumped parameter models of one quarter of the machine have been developed and validated against experimental results, assuming a thermal boundary condition at the machine flange side. The effect of adding thermal paste to the machine end region has been quantified using the thermal lumped parameter model developed in Simulink/Simscape. Key elements of the machine components were represented as sub-blocks in the proposed lumped parameter model.

It is shown that axial heat flow rate is increased $5.6 \%$ for the prototype with added thermal paste in DC thermal tests. This reduced the machine hot spot temperature around $10^{\circ} \mathrm{C}$ during the dc thermal tests. In open circuit tests at rated speed, a significant temperature reduction that is about $22^{\circ} \mathrm{C}$, has been obtained in FE model for the PMA with thermal paste when experimentally predicted iron losses were injected to the stator core. Furthermore, un-potted end windings of the PMA with thermal paste in full speed, short circuit operation gives $30^{\circ} \mathrm{C}$ less temperature rise compared to the prototype alternator without the encapsulation material. The results validate that the encapsulation of end windings with high thermal conductivity materials is an option to reduce the winding temperature for the electrical machines without active cooling.

\section{REFERENCES}

[1] A. Boglietti, A. Cavagnino, D. Staton, M. Shanel, M. Mueller and C. Mejuto, "Evolution and Modern Approaches for Thermal Analysis of Electrical Machines," in IEEE Transactions on Industrial Electronics, vol. 56, no. 3, pp. 871-882, March 2009.

[2] N. J. Baker, D. J. B. Smith, M. C. Kulan and S. Turvey, "Design and Performance of a Segmented Stator Permanent Magnet Alternator for Aerospace," in IEEE Transactions on Energy Conversion, vol. 33, no. 1, pp. 40-48, March 2018.

[3] M.C. Kulan, N.J. Baker, "A Thermal Equivalent Circuit to Quantify the Effect of Thermal Paste on Heat Flow Through a PM Machine, "IEEE International Electric Machines and Drives Conference (IEMDC). 2017, Miami, FL, USA

[4] R. Wrobel, P. Mellor and D. Holliday, "Thermal analysis of a segmented stator winding design," 2010 IEEE Energy Conversion Congress and Exposition, Atlanta, GA, 2010, pp. 1290-1297.

[5] H. Li, K. W. Klontz, V. E. Ferrell and D. Barber, "Thermal Models and Electrical Machine Performance Improvement Using Encapsulation Material," in IEEE Transactions on Industry Applications, vol. 53, no. 2, pp. 1063-1069, March-April 2017.

[6] A. Boglietti, M. Cossale, S. Vaschetto and T. Dutra, "Experimental validation in operative conditions of winding thermal model for shorttime transient," 2016 IEEE Energy Conversion Congress and Exposition (ECCE), Milwaukee, WI, 2016, pp. 1-6.

[7] A. M. EL-Refaie, N. C. Harris, T. M. Jahns and K. M. Rahman, "Thermal analysis of multibarrier interior PM synchronous Machine using lumped parameter model," in IEEE Transactions on Energy Conversion, vol. 19, no. 2, pp. 303-309, June 2004.

[8] F. Qi, A. Stippich, M. Guettler, M. Neubert and R. W. De Doncker, "Methodical considerations for setting up space-resolved lumpedparameter thermal models for electrical machines," Electrical Machines and Systems (ICEMS), 2014 17th International Conference on, Hangzhou, 2014, pp. 651-657.

[9] N. Rostami, M. R. Feyzi, J. Pyrhonen, A. Parviainen and M. Niemela, "Lumped-Parameter Thermal Model for Axial Flux Permanent Magnet 
Machines," in IEEE Transactions on Magnetics, vol. 49, no. 3, pp. 11781184, March 2013.

[10] F.P. Incropera, D.P. DeWitt, T.L. Bergman, and A.S. Lavine, "Fundamentals of Heat and Mass Transfer", 6th Ed., Hoboken, NJ, John Wiley \& Sons, 2007.

[11] S. W. Churchill, H. H. S. Chu, "Correlating equations for laminar and turbulent free convection from a vertical plate," International journal of heat and mass transfer, vol. 18, pp. 1323-1329, 1975.

[12] S. W. Churchill, H. H. S. Chu, "Correlating equations for laminar and turbulent free convection from a horizontal cylinder," International journal of heat and mass transfer, vol. 18, pp. 1049-1053, 1975.

[13] G. Kylander, "Thermal modelling of small cage induction motors," Ph.D. dissertation, School Electr. Comput. Eng., Chalmers Univ. Technol., Goteborg, Sweden, Tech. Rep. 265, Feb. 1995.

[14] J. Lindstom, "Thermal model of a permanent-magnet motor for a hybrid electric vehicle," Dept. Power Eng., Chalmers Univ. Technol., Goteborg, Sweden, Internal Rep., Apr. 1999.

[15] G. D. Demetriades, H. Z. d. 1. Parra, E. Andersson and H. Olsson, "A Real-Time Thermal Model of a Permanent-Magnet Synchronous Motor," in IEEE Transactions on Power Electronics, vol. 25, no. 2, pp. 463-474, Feb. 2010.

[16] W. L. Soong, "Thermal Analysis of Electrical Machines: LumpedCircuit, FE Analysis and Testing." Tc 2.P3: P4

[17] A. Boglietti, A. Cavagnino and D. Staton, "Determination of Critical Parameters in Electrical Machine Thermal Models," in IEEE Transactions on Industry Applications, vol. 44, no. 4, pp. 1150-1159, July-aug. 2008.

[18] M. C. Kulan, N. J. Baker and J. D. Widmer, "Design and Analysis of Compressed Windings for a Permanent Magnet Integrated Starter Generator," in IEEE Transactions on Industry Applications, vol. 53, no. 4, pp. 3371-3378, July-Aug. 2017.

[19] D. Staton, A. Boglietti and A. Cavagnino, "Solving the More Difficult Aspects of Electric Motor Thermal Analysis in Small and Medium Size Industrial Induction Motors," in IEEE Transactions on Energy Conversion, vol. 20, no. 3, pp. 620-628, Sept. 2005.

[20] G. Dajaku and D. Gerling, "An improved lumped parameter thermal model for electrical machines." In 17th International conference on electrical machines (ICEM2006).

[21] N. J. Baker, D. J. Smith, M. C. Kulan and S. Turvey, "Design and performance of a segmented stator permanent magnet alternator for aerospace," 8th IET International Conference on Power Electronics, Machines and Drives (PEMD 2016), Glasgow, 2016, pp. 1-6.

Mehmet C. Kulan received the BSc degree in electrical and electronics engineering from Bilkent University, Ankara, Turkey in 2011 and MSc degree from the University of Newcastle Upon Tyne U.K., in 2013, where he is currently working toward the Ph.D. degree as part of Electrical Power Group, School of Electrical and Electronic Engineering. His research interests include thermal management of electrical machines and finite element modelling of electric motors and generators.

Nick J. Baker received a MEng Degree in Mechanical Engineering from Birmingham University, UK, in 1999 and a Ph.D. from Durham University U.K in 2003 for work in electrical machine design for marine renewable energy devices. $\mathrm{He}$ is presently a Senior Lecturer within Newcastle University's Electrical Power Group. Nick is a machine designer with research projects across the automotive, aerospace and renewable energy sector. 